\title{
URBAN-RURAL BUS PATH PLANNING BASED ON ANT COLONY OPTIMIZATION ALGORITHM
}

\author{
Juan $\operatorname{Li}^{1,2}$, Bo Wei ${ }^{1,2, *}$ \\ ${ }^{1}$ Guangxi Key Laboratory of Spatial Information and Geomatics, Guilin University of Technology, Jiangan Road, Guilin, China - \\ (lijuan170702, superweibo)@glut.edu.cn \\ ${ }^{2}$ College of Geomatics and Geoinformation, Guilin University of Technology, Jiangan Road, Guilin, China
}

Commission VI, WG VI/4

KEY WORDS: Ant Colony Optimization Algorithm, Urban-Rural Public Transport, Path Planning, Analytic Hierarchy Process, Pheromone, Judgment Matrix, Space Shrinkage Transformation

\begin{abstract}
:
With the advancement of urbanization, urban-rural public transport issues have become one of the most critical issues in urban development. The paper makes a detailed study on the optimization of urban-rural bus routes in Erqi District of Zhengzhou, China. The factors of bus stop selection are analyzed, and the three categories, including traffic road condition factors, economic benefit factors and waiting number factors, are mainly considered. The analytic hierarchy process is used to determine 35 specific objectives of urban-rural bus stop optimization, 20 of which are selected for simulation experiment with large weight. Then the ant colony optimization (ACO) algorithm in path optimization is analyzed, which has the following two advantages. First, the global pheromone update is combined with the local pheromone update to enhance the algorithm's optimization ability and convergence speed. Second, through the method of spatial contraction transformation, the ant constructs a solution to reduce the number of construction steps and speed up the operation. Based on the actual analysis of urban-rural public transportation in the Erqi District of Zhengzhou, a simulation experiment is executed to show that the ACO algorithm is able to find out the optimal path, which is $15.1 \%$ shorter than the ant colony system (ACS) algorithm. The ACO algorithm improved path planning has good time effectiveness and path practicability.
\end{abstract}

\footnotetext{
* Corresponding author
}

\section{INTRODUCTION}

With the development of urbanization, an increasing number of rural residents take urban-rural public transportation to work in the cities. The urban-rural public transportation has become one of the most critical issues in urban-rural development. Based on the study of the current situation and the existing routes of urban-rural public transport, an ant colony optimization algorithm (ACO) (Martin, Frank, Hartmut, 2003) for optimal path planning is proposed according to the traffic characteristics of township residents and the analysis of traffic flow in each station, which the constraints of carrying capacity in urban-rural public transport are considered. The ant colony optimization algorithm for optimal path planning is to seek an optimal route for the urban-rural public transportation with the maximum benefit in maximum passenger capacity and short running time.

The ant colony optimization algorithm is a simulation algorithm that optimizes the regularity of ant foraging in nature and mutual cooperation in foraging operations (Feng, Zheng, Liu, 2005). It is a self-organizing algorithm that increases the system without external influences. The ant colony optimization algorithm has strong global search ability and robustness. However, its pheromone is huge and the search time is long, which will lead to the lack of some information and reduce the credibility of the evaluation results. The Analytic Hierarchy Process (AHP) is a hierarchical thinking framework. It is scientific and practical by comparing scales. However, when there are too many evaluation factors, the scale workload is large, which is easy to cause confusion (Yuan, Liu, 2013). If the consideration is insufficient and the matrix judgment is discussed more, the rationality is not enough (Shou, $\mathrm{Fu}, 2010$ ). In the paper, the analytic hierarchy process and the ant colony optimization algorithm are used to complement each other, which are used to determine the weight of the point index in the urban-rural Public Transport path planning, which makes the determination of the selected point weight more objective.

At present, in the ant colony algorithm, the literature (Dorigo et al., 1996) proposed the ant system (AS) algorithm, in which the algorithm selects the path by random method, and updates pheromone after the iteration. The literature (Dorigo et al., 1997) proposed the ant colony optimization (ACO) algorithm, which uses the path selection method combining optimal selection and random selection. The pheromone update adopts local update and global update, which improves the global convergence ability of the algorithm. Some scholars have begun to use AHP for site selection analysis, but these analyses emphasize the analysis of attribute information, while the analysis of weight applications is incompetent. This paper focuses on the analysis of the weight of the station, that bus station with large weight is selected for path planning.

\section{OPTIMIZE THE OBJECTIVE EVALUATION SYSTEM}

Analytic Hierarchy Process (AHP) was proposed by Professor Saaty of the University of Pittsburgh in 1973 (Xia, Wang, et al., 2011). The complex multi-index evaluation problem is taken as a system by constructing a hierarchical structure. The overall goal is decomposed into multiple sub-goals or standards, and 
the corresponding sub-goals are further decomposed into related multiple indicators to form an overall hierarchical model. Through the layer-by-layer analysis, the importance weights are determined from the lowest layer to the highest layer.

\subsection{Evaluation Index System}

According to the selection factors of urban-rural bus station selection, the comprehensive evaluation index system for urbanrural bus station selection is divided into three levels. The second layer is mainly determined by the relevant evaluation criteria for urban-rural bus operations. The third layer is the main evaluation index, that is, the first-level indicator layer such as traffic condition factors, income factors, and waiting number factors. The secondary index layer is an alternative 35 bus stations.

\subsection{Establishment of AHP Model}

Among them, the target layer of bus station selection evaluation system is system name a. the six indexes of the second criterion layer are operating cost B1, vehicle loss B2, traffic feature B3, station performance B4, bus number B5 and passenger satisfaction B6. The three indexes in the third layer are traffic condition $\mathrm{C} 1$, revenue benefit $\mathrm{C} 2$ and waiting number $\mathrm{C} 3$ respectively. The specific Figure 1 below shows the comprehensive evaluation system structure of urban-rural bus station selection.

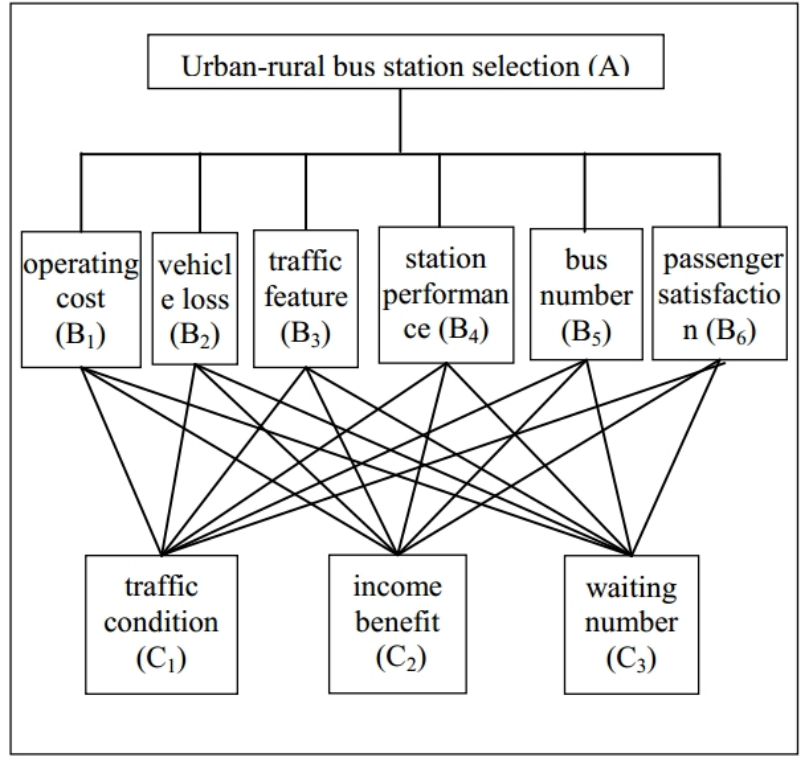

Figure 1. Analytic hierarchy process model

\subsection{Construction Judgment Matrix}

The judgment matrix is used to represent the relative importance of each indicator at the same level to represent value. The AHP method introduces a scale of nine-point scale when judging the relative importance of indicators, that is, 9 means extremely important, 7 means very important, 5 means important, 3 means slightly important, 1 means equal, $1 / 3$ Slightly important, $1 / 5$ minor, $1 / 7$ is secondary, $1 / 9$ is secondary, taking $8,6,4,2,1 / 2,1 / 4,1 / 6,1 / 8$ for the above review the median of value $(\mathrm{Ni}, 2002)$. According to the scale table, all relevant attribute values are compared in pairs, the relative importance of the hierarchical elements is determined, and finally, all the values of the elements of each level are given.
As shown in Table 1, the pairwise comparison matrix $A-B_{1-6}$, where $\mathrm{CR}=0.0470, \mathrm{~A}=$ urban-rural bus station selection, $\mathrm{B} 1=$ operating cost, $\mathrm{B} 2=$ vehicle loss, $\mathrm{B} 3=$ traffic feature, $\mathrm{B} 4=$ station performance, $\mathrm{B} 5=$ bus number and $\mathrm{B} 6=$ passenger satisfaction. $\mathrm{W}_{\mathrm{A}}$ is the weight of $\mathrm{B}_{1}-\mathrm{B}_{6}$ to $\mathrm{A}$.

\begin{tabular}{|c|c|c|c|c|c|c|c|}
\hline $\mathrm{A}$ & $\mathrm{B}_{1}$ & $\mathrm{~B}_{2}$ & $\mathrm{~B}_{3}$ & $\mathrm{~B}_{4}$ & $\mathrm{~B}_{5}$ & $\mathrm{~B}_{6}$ & $\mathrm{~W}_{\mathrm{A}}$ \\
\hline $\mathrm{B}_{1}$ & 1 & 1 & 1 & $1 / 3$ & $1 / 3$ & $1 / 3$ & 0.0942 \\
$\mathrm{~B}_{2}$ & 1 & 1 & $1 / 2$ & $1 / 2$ & $1 / 3$ & 1 & 0.099 \\
$\mathrm{~B}_{3}$ & 1 & 2 & 1 & 1 & 1 & 1 & 0.1775 \\
$\mathrm{~B}_{4}$ & 3 & 2 & 1 & 1 & 1 & 3 & 0.2453 \\
$\mathrm{~B}_{5}$ & 3 & 3 & 1 & 1 & 1 & 2 & 0.242 \\
$\mathrm{~B}_{6}$ & 3 & 1 & 1 & $1 / 3$ & $1 / 2$ & 1 & 0.142 \\
\hline
\end{tabular}

Table 1. The pairwise comparison matrix $\mathrm{A}-\mathrm{B}_{1-6}$

As shown in Table 2, the pairwise comparison matrix $\mathrm{C}_{1-3}-\mathrm{B}_{1}$, where $\mathrm{CR}=0.0470, \mathrm{~B}_{1}=$ operating cost, $\mathrm{C}_{1}=$ traffic condition, $\mathrm{C}_{2}=$ income benefit and $\mathrm{C}_{3}=$ waiting number. $\mathrm{W}_{\mathrm{B} 1}$ is the weight of $\mathrm{C}_{1}-\mathrm{C}_{3}$ to $\mathrm{B}_{1}$.

\begin{tabular}{|c|c|c|c|c|}
\hline $\mathrm{B}_{1}$ & $\mathrm{C}_{1}$ & $\mathrm{C}_{2}$ & $\mathrm{C}_{3}$ & $\mathrm{~W}_{\mathrm{B} 1}$ \\
\hline $\mathrm{C}_{1}$ & 1 & $1 / 9$ & $1 / 2$ & 0.074 \\
$\mathrm{C}_{2}$ & 9 & 1 & 9 & 0.8084 \\
$\mathrm{C}_{3}$ & 2 & $1 / 9$ & 1 & 0.1176 \\
\hline
\end{tabular}

Table 2. The pairwise comparison matrix $\mathrm{C}_{1-3}-\mathrm{B}_{1}$

As shown in Table 3 , the pairwise comparison matrix $\mathrm{C}_{1-3}-\mathrm{B}_{2}$, where $\mathrm{CR}=0.0790, \mathrm{~B}_{2}=$ vehicle loss, $\mathrm{C}_{1}=$ traffic condition, $\mathrm{C}_{2}$ $=$ income benefit and $\mathrm{C}_{3}=$ waiting number. $\mathrm{W}_{\mathrm{B} 2}$ is the weight of $\mathrm{C}_{1}-\mathrm{C}_{3}$ to $\mathrm{B}_{2}$.

\begin{tabular}{|c|c|c|c|c|}
\hline $\mathrm{B}_{2}$ & $\mathrm{C}_{1}$ & $\mathrm{C}_{2}$ & $\mathrm{C}_{3}$ & $\mathrm{~W}_{\mathrm{B} 2}$ \\
\hline $\mathrm{C}_{1}$ & 1 & $1 / 9$ & $1 / 2$ & 0.074 \\
$\mathrm{C}_{2}$ & 9 & 1 & 9 & 0.8084 \\
$\mathrm{C}_{3}$ & 2 & $1 / 9$ & 1 & 0.1176 \\
\hline
\end{tabular}

Table 3. The pairwise comparison matrix $\mathrm{C}_{1-3}-\mathrm{B}_{2}$

As shown in Table 4, the pairwise comparison matrix $\mathrm{C}_{1-3}-\mathrm{B}_{3}$, where $\mathrm{CR}=0.0089, \mathrm{~B}_{3}=$ traffic feature, $\mathrm{C}_{1}=$ traffic condition, $\mathrm{C}_{2}=$ income benefit and $\mathrm{C}_{3}=$ waiting number. $\mathrm{W}_{\mathrm{B} 3}$ is the weight of $\mathrm{C}_{1}-\mathrm{C}_{3}$ to $\mathrm{B}_{3}$.

\begin{tabular}{|c|c|c|c|c|}
\hline $\mathrm{B}_{3}$ & $\mathrm{C}_{1}$ & $\mathrm{C}_{2}$ & $\mathrm{C}_{3}$ & $\mathrm{~W}_{\mathrm{B} 3}$ \\
\hline $\mathrm{C}_{1}$ & 1 & 1 & 3 & 0.416 \\
$\mathrm{C}_{2}$ & 1 & 1 & 4 & 0.4577 \\
$\mathrm{C}_{3}$ & $1 / 3$ & $1 / 4$ & 1 & 0.1263 \\
\hline
\end{tabular}

Table 4 . The pairwise comparison matrix $\mathrm{C}_{1-3}-\mathrm{B}_{3}$

As shown in Table 5, the pairwise comparison matrix $\mathrm{C}_{1-3}-\mathrm{B}_{4}$, where $\mathrm{CR}=0.0358, \mathrm{~B}_{4}=$ station performance, $\mathrm{C}_{1}=$ traffic condition, $\mathrm{C}_{2}$ = income benefit and $\mathrm{C}_{3}=$ waiting number. $\mathrm{W}_{\mathrm{B} 4}$ is the weight of $\mathrm{C}_{1}-\mathrm{C}_{3}$ to $\mathrm{B}_{4}$.

\begin{tabular}{|c|c|c|c|c|}
\hline $\mathrm{B}_{4}$ & $\mathrm{C}_{1}$ & $\mathrm{C}_{2}$ & $\mathrm{C}_{3}$ & $\mathrm{~W}_{\mathrm{B} 4}$ \\
\hline $\mathrm{C}_{1}$ & 1 & $1 / 4$ & 4 & 0.22 \\
$\mathrm{C}_{2}$ & 4 & 1 & 9 & 0.7132 \\
$\mathrm{C}_{3}$ & $1 / 4$ & $1 / 9$ & 1 & 0.0669 \\
\hline
\end{tabular}

Table 5. The pairwise comparison matrix $\mathrm{C}_{1-3}-\mathrm{B}_{4}$ 
As shown in Table 6, the pairwise comparison matrix $\mathrm{C}_{1-3}-\mathrm{B}_{5}$, where $\mathrm{CR}=0.0337, \mathrm{~B}_{5}=$ Bus Number, $\mathrm{C}_{1}=$ Traffic condition, $\mathrm{C}_{2}=$ income benefit and $\mathrm{C}_{3}=$ waiting number. $\mathrm{W}_{\mathrm{B} 5}$ is the weight of $\mathrm{C}_{1}-\mathrm{C}_{3}$ to $\mathrm{B}_{5}$.

\begin{tabular}{|c|c|c|c|c|}
\hline $\mathrm{B}_{5}$ & $\mathrm{C}_{1}$ & $\mathrm{C}_{2}$ & $\mathrm{C}_{3}$ & $\mathrm{~W}_{\mathrm{B} 5}$ \\
\hline $\mathrm{C}_{1}$ & 1 & 7 & 1 & 0.4981 \\
$\mathrm{C}_{2}$ & $1 / 7$ & 1 & $1 / 4$ & 0.087 \\
$\mathrm{C}_{3}$ & 1 & 4 & 1 & 0.4148 \\
\hline
\end{tabular}

Table 6. The pairwise comparison matrix $\mathrm{C}_{1-3}-\mathrm{B}_{5}$

As shown in Table7, the pairwise comparison matrix $\mathrm{C}_{1-3}-\mathrm{B}_{6}$, where $\mathrm{CR}=0.0914, \mathrm{~B}_{6}=$ passenger satisfaction, $\mathrm{C}_{1}=$ traffic condition, $\mathrm{C}_{2}=$ income benefit and $\mathrm{C}_{3}=$ waiting number. $\mathrm{W}_{\mathrm{B} 6}$ is the weight of $\mathrm{C}_{1}-\mathrm{C}_{3}$ to $\mathrm{B}_{6}$.

\begin{tabular}{|c|c|c|c|c|}
\hline $\mathrm{B}_{6}$ & $\mathrm{C}_{1}$ & $\mathrm{C}_{2}$ & $\mathrm{C}_{3}$ & $\mathrm{~W}_{\mathrm{B} 6}$ \\
\hline $\mathrm{C}_{1}$ & 1 & 0.2 & 1 & 0.1702 \\
$\mathrm{C}_{2}$ & 5 & 1 & 2 & 0.6008 \\
$\mathrm{C}_{3}$ & 1 & 0.5 & 1 & 0.229 \\
\hline
\end{tabular}

Table 7. The pairwise comparisons matrix $\mathrm{C}_{1-3}-\mathrm{B}_{6}$

\subsection{Indicator Calculate and Consistency Check}

The analytic hierarchy process is used to determine 35 specific objectives of urban-rural bus stop optimization, 20 of which are selected for simulation experiment with large weight. Table 8 shows the calculated total weight index of each site $\mathrm{Di}, 20$ of which are very large, and the weight indicators of each site $\mathrm{D}_{\mathrm{i}-}$ $\mathrm{C} 1, \mathrm{D}_{\mathrm{i}}-\mathrm{C} 2, \mathrm{D}_{\mathrm{i}}-\mathrm{C} 3$, where $\mathrm{W}_{\mathrm{i}}=$ criteria weight, $\mathrm{D}_{1}=$ Sanli, $\mathrm{D}_{2}=$ Tongshuwa, $\mathrm{D}_{3}=$ Arboretum, $\mathrm{D}_{4}=$ the First City, $\mathrm{D}_{5}=$ Huang Gang Temple, $\mathrm{D}_{6}=$ Asia Star Square, $\mathrm{D}_{7}=$ Houzhai, $\mathrm{D}_{8}=$ Guoxioazhai, $\mathrm{D}_{9}=$ Zheng-mi Station, $\mathrm{D}_{10}=$ Houzhang Line Hubin Road, $\mathrm{D}_{11}=$ Zhang Xian, $\mathrm{D}_{12}=$ Erqiwanda, $\mathrm{D}_{13}=$ Cherry Vale, $\mathrm{D}_{14}=$ University Road South Third Ring Road, $\mathrm{D}_{15}=$ South Songshan Road, $\mathrm{D}_{16}=$ Song Shan South Road Yuanzhai, $\mathrm{D}_{17}=$ Medical College, $\mathrm{D}_{18}=$ Lucheng Square, $\mathrm{D}_{19}=$ Bei-guang South Road, $\mathrm{D}_{20}=$ West Square of Railway Station.

\section{PATH OPTIMIZATION METHOD BASED ON ANT COLONY OPTIMIZATION ALGORITHM}

\subsection{Basic Principles of Ant Colony Algorithm}

In nature, ant colonies seek the shortest path from ant colony to food through information exchange and collaboration between individuals. During the movement, ants can leave a substance called "pheromone" on the path they are passing through, and each ant can perceive the existence and intensity of the pheromone and will have a high intensity toward the pheromone (Abreu, 1996). The direction of movement, in the process of a large number of ants collectively foraging, the more ants that pass through a certain path, the greater the chance that later ants will choose the path, thus leaving more pheromones (Russo, 1996). In the next time, the possibility that this path is selected by other ants is greater, and finally it is determined to be the shortest path selected by all ants (Russo, 1999).

\subsection{Ant Colony Optimization Algorithm Process}

\subsubsection{The Process of Constructing a Problem Solution}

The ant adopts a pseudo-random ratio rule strategy. The rule of the $\mathrm{k}$ ant selects the next city $\mathrm{j}$ in the city $\mathrm{I}$, such as formula (1).

\begin{tabular}{|c|c|c|c|c|}
\hline Goal D & $\mathrm{C} 1$ & $\mathrm{C} 2$ & $\mathrm{C} 3$ & $\mathrm{Wi}$ \\
\hline $\begin{array}{c}\text { Error! No } \\
\text { bookmark } \\
\text { name } \\
\text { given. }\end{array}$ & 0.1099 & 0.1331 & 0.1557 & 0.1306 \\
$\mathrm{D}_{2}$ & 0.1205 & 0.1331 & 0.0472 & 0.1131 \\
$\mathrm{D}_{3}$ & 0.0712 & 0.0881 & 0.0511 & 0.0761 \\
$\mathrm{D}_{4}$ & 0.0702 & 0.0881 & 0.0511 & 0.0758 \\
$\mathrm{D}_{5}$ & 0.0853 & 0.0371 & 0.1557 & 0.0738 \\
$\mathrm{D}_{6}$ & 0.0755 & 0.0371 & 0.0698 & 0.0546 \\
$\mathrm{D}_{7}$ & 0.0594 & 0.0541 & 0.0472 & 0.0543 \\
$\mathrm{D}_{8}$ & 0.0509 & 0.0523 & 0.0495 & 0.0513 \\
$\mathrm{D}_{9}$ & 0.0495 & 0.0361 & 0.0472 & 0.0421 \\
$\mathrm{D}_{10}$ & 0.0363 & 0.0523 & 0.0204 & 0.0415 \\
$\mathrm{D}_{11}$ & 0.0375 & 0.027 & 0.0505 & 0.0345 \\
$\mathrm{D}_{12}$ & 0.0188 & 0.0225 & 0.0742 & 0.0312 \\
$\mathrm{D}_{13}$ & 0.0293 & 0.0361 & 0.0136 & 0.0298 \\
$\mathrm{D}_{14}$ & 0.0240 & 0.0349 & 0.0127 & 0.0275 \\
$\mathrm{D}_{15}$ & 0.0350 & 0.027 & 0.0143 & 0.0269 \\
$\mathrm{D}_{16}$ & 0.0179 & 0.0267 & 0.0127 & 0.0215 \\
$\mathrm{D}_{17}$ & 0.0178 & 0.0192 & 0.0312 & 0.0210 \\
$\mathrm{D}_{18}$ & 0.0161 & 0.0187 & 0.0319 & 0.0204 \\
$\mathrm{D}_{19}$ & 0.0163 & 0.0145 & 0.0319 & 0.0183 \\
$\mathrm{D}_{20}$ & 0.0171 & 0.0083 & 0.0127 & 0.0117 \\
\hline
\end{tabular}

Table 8. Criteria weights of all bus stations

$$
j=\left\{\begin{array}{l}
\arg \max \left\{\tau_{i s}^{\alpha}, \eta_{s \in N_{i}^{k}}^{\beta}\right\}, q \leq q_{o} \\
J
\end{array}\right.
$$

where $\quad \tau=$ the pheromone intensity

$\eta=$ heuristic information

$\mathbf{J}=\mathrm{a}$ random variable determined according to equation

$\alpha$ is the relative importance parameter of the pheromone accumulated in the ant selection path during the movement of the ant; $\beta$ is the relatively important parameter of the heuristic information in the selection path; $\mathrm{N}$ is located in the city The ant $\mathrm{k}$ of $\mathrm{i}$ can directly reach the collection of neighboring cities, $\mathrm{q}_{0}$ $\in(0,1)$ is a constant, $\mathrm{q} \in(0,1)$ is a random number. By adjusting the parameter $\mathrm{q}_{0}$, the adjusting degree of the algorithm to the new path can be adjusted. Obviously, this strategy enhances the diversity of the search to avoid premature search stagnation.

\subsubsection{Local Pheromone Update}

The effect of the local pheromone update is to make the selected edge have less influence on the later ants so that the ants have a stronger ability to explore the unselected edges (Cecilia, Nisbet, Amos, 2013). When the ant moves from city $i$ to city $j$, the pheromone on the side $(i, j)$ is updated as follows (2):

$$
\tau_{i j}=(1-\xi) \square \tau_{i j}+\xi \square \tau_{0}
$$

where $\quad \xi=$ a parameter that satisfies $0<\xi<1$

$\tau_{0}=$ the initial value of the pheromone quantity 


\subsubsection{Global Pheromone Update}

After the end of the iteration, the current optimal path is used to update the pheromone globally.

$$
\begin{gathered}
\tau_{i j}=(1-\rho) \square \tau_{i j}+\rho \square \Delta \tau_{i j} \\
\Delta \tau_{i j}=\frac{L_{1}-L_{R}}{L_{R}}
\end{gathered}
$$

where $0<\xi<1 \rho=$ the globally updated evaporation rate $\Delta \tau_{i j}=$ the global update pheromone increment $\mathrm{L}_{1}=$ the current iteration optimal path length $\mathrm{L}_{\mathrm{R}}=$ the current optimal path length

Updating the pheromone on the current optimal path lies in the continuation of the development of the optimal path, and the feedback of the current optimal path to the information element is retained until the next iteration until a better path is replaced. Used in conjunction with local pheromone updates, the algorithm's ability to optimize and convergence speed is enhanced.

\subsubsection{Space Shrinkage Transformation Method}

The spatial contraction transformation method is to set a weighted value $\omega^{*}$, and the algorithm updates the building block weight (implicit pheromone update) after each run. After the algorithm runs a certain number of algebras, and all component weights are compared with the weighted value $\omega^{*}$, and all the building weights are greater than the corresponding weights $\omega^{*}$ recombination, thus combining the extended building blocks, so that the construction of the algorithm solution is still in a simple space. Repeat the operation until the conditions are met (Zhao, Yang, Liu, 2013).

\subsection{Algorithm Steps}

The ant colony optimization algorithm uses the standard ACS algorithm as the basic framework to improve the design (Zhao, Yang, Liu, 2013). The specific algorithm operation steps can be summarized as follows:

1. Parameter initialization. Let the iteration counter $\mathrm{NC}=0$, set the current optimal path length $\mathrm{S}$, the maximum number of iterations $T$, the distance $\mathrm{d}_{\mathrm{ij}}$ between cities ( $\mathrm{i}$, $\mathrm{j}=1, \ldots, \mathrm{n})$, the current optimal path table $t$, the heuristic information $\prod_{i j}(i, j=1,2, \ldots, n)$, pheromone $\tau_{i j}(i, j=1$, $2, \ldots, n)$ on the path.

2. The ant position is initialized. Initialize $m$ ants' taboo table $\mathrm{t}_{\mathrm{k}}(\mathrm{k}=1,2, \ldots, \mathrm{m})$ and the path length $\mathrm{L}_{\mathrm{k}}(\mathrm{k}=1,2, \ldots$, $\mathrm{m})$.

3. The localization algorithm is used to locally optimize the construction solution. Each ant performs path selection according to equation (1), adds the selected city to $T_{k}$, and updates the value of $\mathrm{L}_{\mathrm{k}}$.

4. The pheromone is partially updated. Each time the salesperson selects a city, the pheromone is partially updated according to formula (2) just after the path (i, j).

5. The pheromone is dynamically updated globally. The pheromone global dynamic update is performed according to the formulas (3) and (4) for the current optimal path.

6. Whether the space contraction construction condition is satisfied. If it is satisfied, the weight is calculated and the building block weight is updated.
7. Iterate loop. If $\mathrm{NC}<=\mathrm{T}$, return to Step2 and start a new iteration, otherwise the algorithm ends and output the optimal path and the average path table.

The specific process of path planning based on ant colony optimization algorithm is shown in Figure 2.

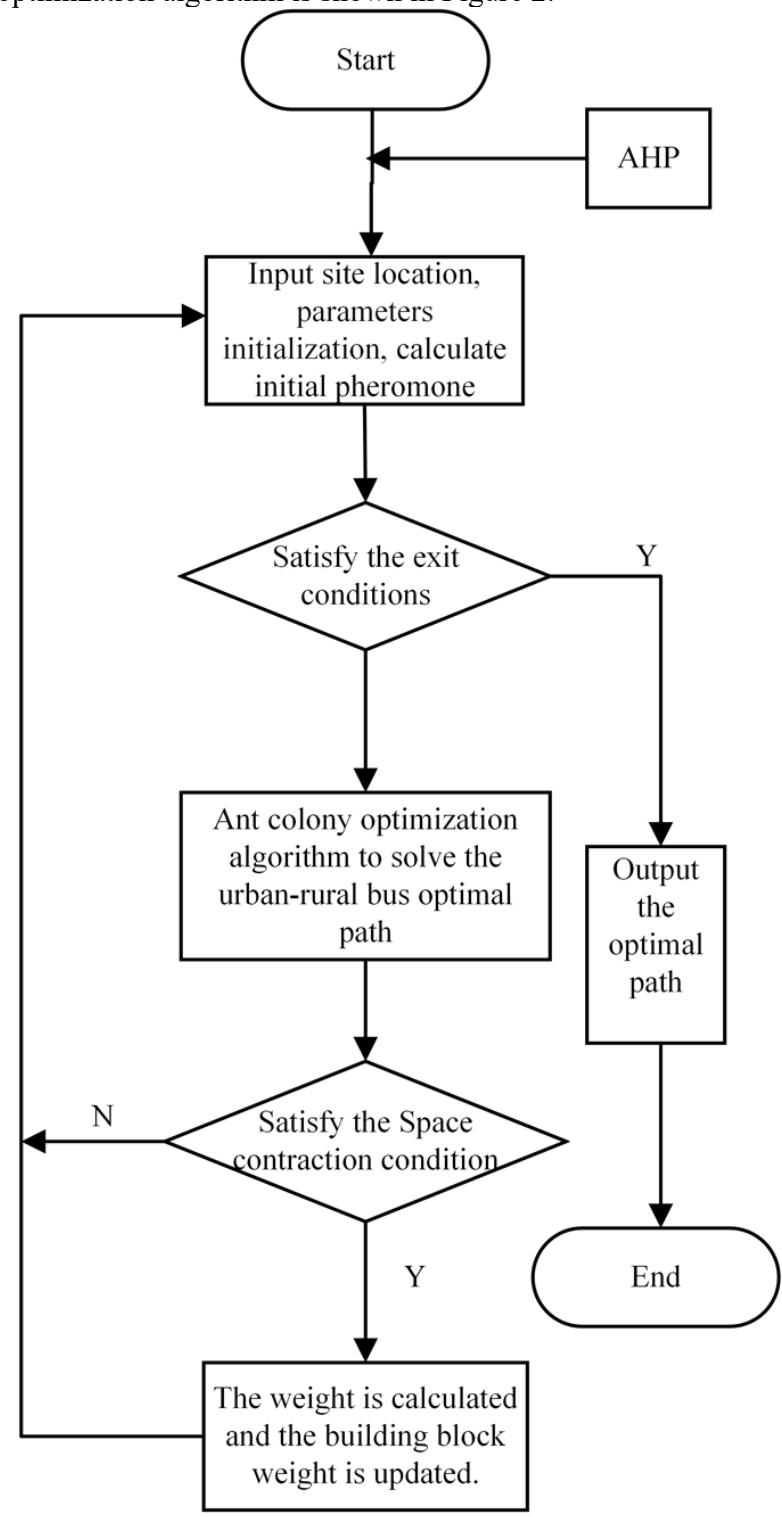

Figure 2. Ant colony optimization algorithm to solve the optimal path flow chart for the urban-rural bus

\subsection{Ant Colony Optimization Algorithm Solves the TSP Problem.}

The traveling salesman problem is one of the most studied problems in computational mathematics (Gregory, Abraham, 2002). The algorithm will select a standard example from the common data set of the traveling salesman problem for test, and make it be programmed with $\mathrm{BCB}+$ Matlab, and the CPU is IntelCeleron $1.0 \mathrm{G}$ runs on the computer with $512 \mathrm{M}$ memory. The experimental parameter is $\mathrm{p}=0.1$ to 0.2 . $\xi \in 0.1 \sim 04, \beta=$ $2 \sim 5, \mathrm{~m}=15 \sim 30, \mathrm{q}_{0}=0.7 \sim 0.95$.

Figure 3 depicts the best path for the algorithm to STP studies in eil51, kroA100, d198 and pcb442. Figure 4 denotes the optimal route of urban-rural bus and the relationship between the 
shortest distance or the average distance and iteration number. When selecting some examples from the dataset and running each set of examples 10 times, such as eil51, kroA100, d198, pcb442, Table 9 depicts the optimal solution and mean that ant colony optimization algorithm (ACO) compares with ant colony system algorithm (ACS).

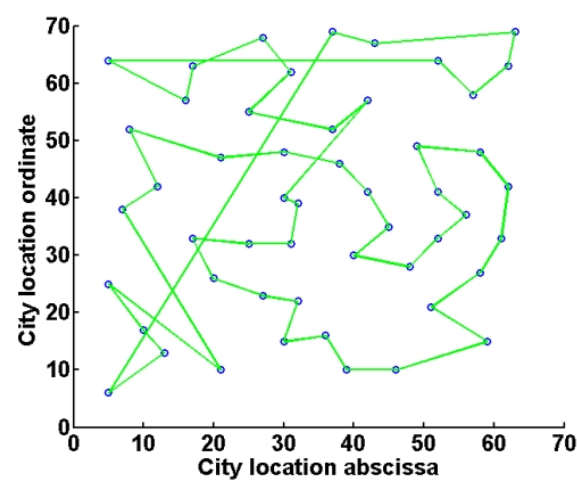

(a)

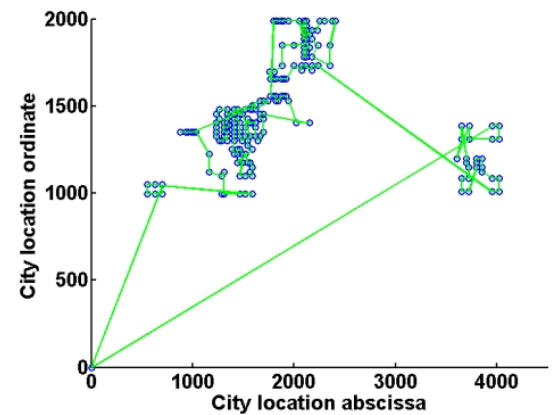

(c)

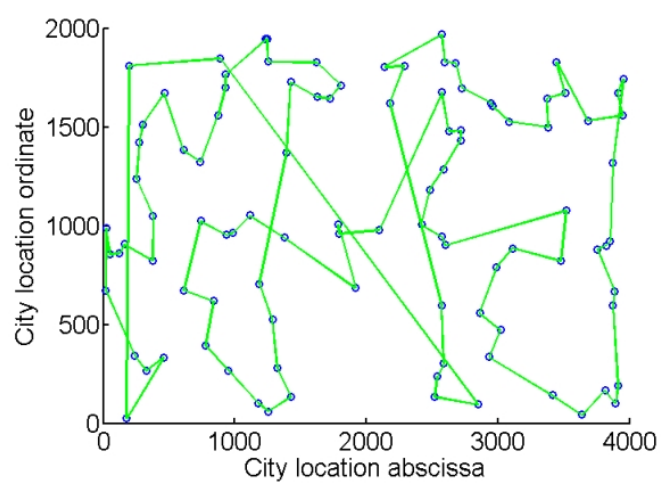

(b)

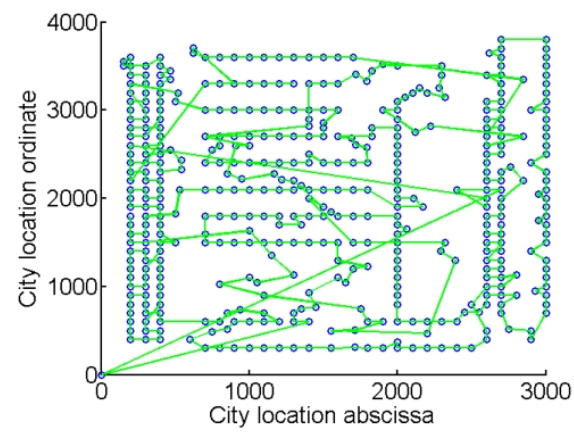

(d)

Figure 3. Denotes the optimal route of eil51 (a), kroA100 (b), d198 (c) and pcb442 (d)
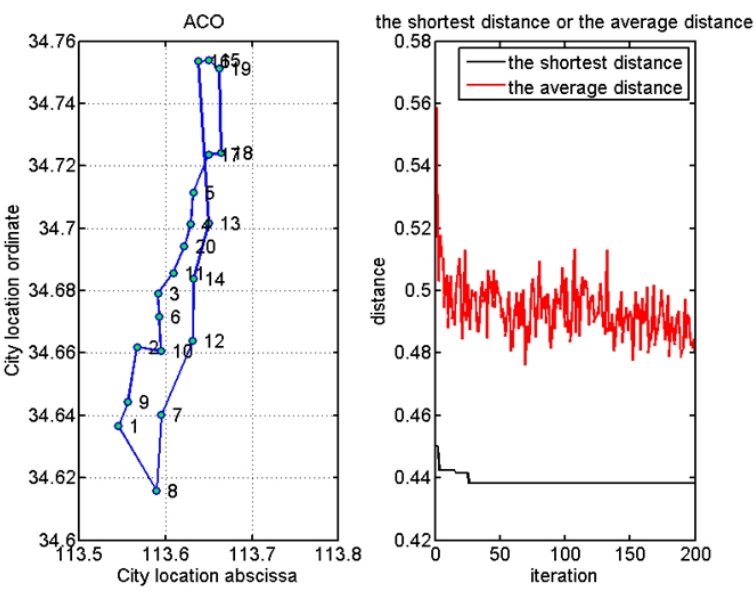

Figure 4. Denotes the optimal route of urban-rural bus

\begin{tabular}{|c|c|c|c|}
\hline $\begin{array}{c}\text { The TSP } \\
\text { problem. }\end{array}$ & Algorithm & $\begin{array}{c}\text { optimal } \\
\text { solution }\end{array}$ & mean \\
\cline { 1 - 2 } eil51 & ACS & 428.871 & 430.891 \\
& ACO & 428.871 & 431.953 \\
kroA100 & ACS & 21621.360 & 21480.203 \\
& ACO & 21002.250 & 21056.258 \\
d198 & ACS & 15893.445 & 15456.238 \\
& ACO & 15106.153 & 15301.562 \\
\cline { 1 - 1 } pcb442 & ACS & 51156.583 & 51522.856 \\
& ACO & 50905.458 & 50966.537 \\
\hline
\end{tabular}

Table 9. Best results for algorithm on various instances

\section{CONCLUSIONS}

Based on the actual analysis of urban-rural public transportation in the Erqi District of Zhengzhou City, China, which is used to determine 20 specific objectives of urban-rural bus stop with large weight, the simulation experiment shows that the ant colony optimization algorithm of the optimal urban-rural bus route is $43.8 \mathrm{~km}$. The ant colony optimization algorithm is able to find out the optimal path, which is $15.1 \%$ shorter than the ant colony system algorithm with the $50.4 \mathrm{~km}$ of bus route.

The ant colony optimization algorithm for path planning has good time effectiveness and path practicability. The feasibility of applying the ant colony optimization algorithm for path planning to the urban-rural public transportation system is verified, and a good balance among remarkable economical benefit, time efficiency and practicability of the path are achieved, expected to be popularized and applied in modern urban-rural public transportation.

\section{ACKNOWLEDGEMENTS}

This work was supported by the National Natural Science Foundation of Chinaunder grant number 41461085; the Natural Science Foundation of Guangxi Provinceunder grant number 2016GXNSFAA380035; the Foundation of Guangxi Key Laboratory of Spatial Information and Geomatics under grant number 16-380-25-04; the "BaGui Scholars" Special Funds of Guangxi Provinceunder grant number 2019-79; and the Doctoral Foundation of Guilin University of Technologyunder grant number 1996015 


\section{REFERENCES}

Abreu, E., Lightstone, M., Mitra, S. K., Arakawa, K., 1996. A new efficient approach for the removal of impulse noise from highly corrupted images. Image Processing, 5(6), 1012-1025.

Cecilia, J. M., Nisbet, A., Amos, M., 2013. Enhancing data parallelism for ant colony optimization on GPUs. Journal of Parallel and Distributed Computing, 73(1), 42-51.

Dorigo, M., Maniezzo, V., Colorni, A., 1996. Ant system: optimization by a colony of cooperating agents. IEEE Transactions on Systems, Man, and Cybernetics, 26 (1), 29-41.

Dorigo, M., Gambardella, L. M., 1997. Ant colony system: a cooperative learning approach to the traveling salesman problem. IEEE Transactions on Evolutionary Computation, 1 (1), 53-66.

Feng, Z. M., Zheng, H. X., 2005. Agricultural water resource based on genetic projection tracing model comprehensive evaluation of source utilization efficiency. Journal of Agricultural Engineering, 21(3), 66-70.

Gregory, G., Abraham, P., 2002: The Traveling Salesman Problem and its Variations. Springer Science \& Business Media, Berlin.

Martin. M., Frank. R., Hartmut. S., 2002. Multi colony ant algorithms. Journal of Heuristics, 8(3), 305-320.

Ni, S. K., 2002. Comparison of seven methods to determine the weight of evaluation indexes. South China Preventive Medicine, 28(6), 54-55.

Russo, F., Ramponi, G., 1996. A fuzzy filter for images corrupted by impulse noise. IEEE Signal Processing Letter, 3(6), 168-170.

Russo, F., 1999. FIRE operators for image processing. Fuzzy Sets System, 103(2), 265-275.

Shou, Y. Y., Fu, A., 2010. Multi-population ant colony algorithm for multi-objective resource-constrained project scheduling. Journal of Zhejiang University: engineering, 44(1), $51-55$.

Xia, P., Wang, K., Li, N. X., Wu, D. R., 2011. An improvement of weights in analytic hierarchy process. Health Htatistics in China, 28(2), 151-157.

Yuan, X., Liu, X., 2013. Ant colony algorithm based pumping station operation optimization and projection pursuit optimization strategy. Journal of agricultural machinery, 44(3), $38-44$.

Zhao, Y. X., Yang, X. S., Liu, L. Q., 2013: Emerging MetaHeuristic Optimization Method. Science Press, Beijing. 